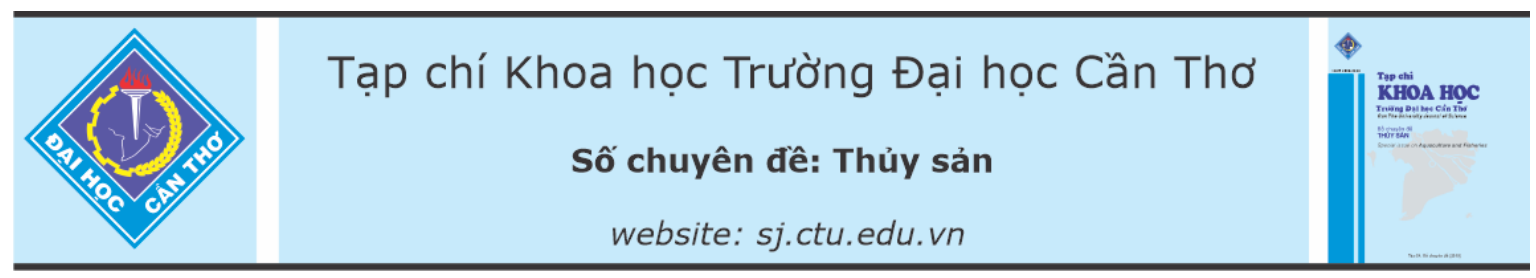

DOI:10.22144/ctu.jvn.2021.060

\title{
NGHIÊN CỨU ƯƠNG ẤU TRÙNG TÔM THẺ CHÂN TRÁNG (Litopenaeus vannamei Boone, 1931) THEO CÔNG NGHỆ BIOFLOC BÀNG CÁCH BỔ SUNG ĐƯờNG CÁT ĐỂ ĐẠT CÁC TỶ LỆ C/N KHÁC NHAU
}

\author{
Châu Tài Tảo, Nguyễn Văn Hòa và Trần Ngọc Hải* \\ Khoa Thủy sản, Truờng Đại hoc Cần Tho \\ *Người chịu trách nhiệm về bài viết: Trần Ngoc Hải (email: tnhai@ctu.edu.vn)
}

\section{Thông tin chung:}

Ngày nhận bài: $22 / 02 / 2021$

Ngày nhận bài sủa: 22/04/2021

Ngày duyệt đăng: 01/06/2021

\section{Title:}

Study on nursing white leg shrimp (Litopenaeus vannamei Boone, 1931) larvae applying biofloc technology by supplementation of sugar to achieve different $\mathrm{C} / \mathrm{N}$ ratio

\section{Tù khóa:}

Áu trùng, biofloc, đuoòng cát, tôm thẻ chân trắng, tỷ lẹ $C / N$ khác nhau

\section{Keywords:}

Biofloc, different $\mathrm{C} / \mathrm{N}$ ratio, larvae, sugar, white leg shrimp

\begin{abstract}
The study is aimed to determine the supplementation of sugar to achieve a ratio of $C / N$ for the best growth and survival of white leg shrimp larvae and postlarvae. The experiment included five treatments of sugar supplement to achieve different $\mathrm{C} / \mathrm{N}$ ratios as 10, 15, 20, 25, and 30; each treatment was triplicated; stocking density was 150 larvae/liter, and water salinity was 30\%; the experimental tank was $0.5 \mathrm{~m}^{3}$ in volume. Results of the experiment showed that the body length of postlarvae 12 $(10.53 \pm 0.07 \mathrm{~mm})$ in the sugar treatment to achieve $C / N=20$ was the highest and significantly different $(p>0.05)$ compared to the sugar treatments with $C / N=10$, and $C / N=15$. The survival rate $(60.9 \pm 1.4 \%)$ and productivity $\left(91,449 \pm 2,094 \mathrm{ind} / \mathrm{m}^{3}\right)$ of $P L-12$ in the sugar treatment with $C / N=20$ were also the highest and significantly different $(p<0.05)$ compared to those of the others. This study showed that the sugar treatment to achieve $\mathrm{C} / \mathrm{N}=20$ was for nursing white-leg shrimp larvae in biofloc systems.
\end{abstract}

\section{TÓM TÁT}

Nghiên cưu nhằm xác định bổ sung đường cát để đạt tỷ lệ C/N thich hợp cho tăng trưởng và tỷ lệ sống của ấu trùng và hậu ấu trùng tôm thẻ chân trắng. Thi nghiệm gồm 5 nghiệm thức bổ sung đường cát với tỷ lệ $C / N$ khác nhau là 10; 15, 20, 25 và 30, mỗi nghiệm thức được lăp lại 3 lần, mật độ $150 \mathrm{con} / L$, độ mặn $30 \%$, bể uoong có thể tích $0,5 \mathrm{~m}^{3}$. Kết quả nghiên cứu cho thấy chiều dài $P L-12(10,53 \pm 0,07 \mathrm{~mm})$ cao nhất ở nghiệm thức bổ sung đường cát để đạt tỷ lẹ $C / N=20$ khác biệt có ý nghĩa thống kê $(p>0,05)$ so với nghiệm thức $C / N=10$ và $C / N=15$. Tỷ lệ sống $(60,9 \pm 1,4$ \%) và năng suất $\left(91.449 \pm 2.094 \mathrm{con} / \mathrm{m}^{3}\right)$ của $P L-12$ cao nhất ở nghiệm thức bổ sung đường cát $C / N=20$, khác biệt có ý nghĩa thống kê $(p<0,05)$ so với các nghiệm thức còn lại. Nghiên cứu cho thấy rằng bổ sung đương cát để đạt tỷ lệ $C / N=20$ trong uoong ấu trùng tôm thẻ chân trắng theo công nghẹ biofloc là tốt nhất.

\section{GIỚI THIỆ}

Tôm thẻ chân trắng là một trong những đối tượng nuôi phổ biến trên thế giới và Việt Nam với mô hình nuôi siêu thâm canh đang phát triển rất mạnh, do đó nhu cầu tôm giống ngày càng tăng. Năm 2017 số trại giống tôm thẻ chân trắng là 561 
trại, đạt sản lượng 54,2 tỷ PL (Tổng cục Thủy sản, 2017). Tuy nhiên, trong những năm qua, nghề nuôi tôm thẻ chân trắng gặp rất nhiều trở ngại do dịch bệnh, số lượng và chất lượng con giống chưa được đảm bảo. Vì thế việc tìm các giải pháp cho nghề sản xuất giống tôm phát triển theo hướng an toàn sinh học là rất cần thiết. Trong đó, công nghệ biofloc được áp dụng trong nuôi trồng thủy sản được xem là công nghệ mới, biofloc có vai trò quan trọng trong việc ổn định môi trường nước, an toàn sinh học, ngăn ngừa mầm bệnh, làm thức ăn trực tiếp cho tôm, tăng cường dưỡng chất tự nhiên, giảm ô nhiễm môi trường (McIntosh et al., 2000). Chính vì thế, việc ứng dụng công nghệ biofloc trong ương ấu trùng tôm thẻ chân trắng nhằm tạo ra con giống tốt phục vụ cho nghề nuôi tôm là rất cần thiết. Theo Châu Tài Tảo và ctv. (2020) đã xác định được nguồn carbon từ đường cát bổ sung vào bể ương ấu trùng tôm thẻ chân trắng là tốt nhất, tuy nhiên cần có thêm nghiên cứu để xác định được tỷ lệ $\mathrm{C} / \mathrm{N}$ thích hợp cho âu trùng và hậu ấu trùng tôm tăng trưởng tốt và tỷ lệ sống cao, góp phần xây dựng qui trình sản xuất giống tôm thẻ chân trắng theo công nghệ biofloc để ứng dụng vào thực tế sản xuất.

\section{PHƯƠNG PHÁP NGHIÊN CÚU}

\subsection{Nguồn nước ương ấu trùng tôm thẻ chân trắng}

Nước ương tôm có độ mặn 30\%o được pha từ nguồn nước ngọt và nước có độ mặn cao $(80 \%)$ từ ruộng muối ở huyện Vĩnh Châu, tỉnh Sóc Trăng. Nước sau khi pha được xử lý bằng chlorine $50 \mathrm{ppm}$ và sục khí mạnh cho đến khi hết chlorine trong nước, dùng sodium bicarbonate $\left(\mathrm{NaHCO}_{3}\right)$ nâng độ kiềm trong nước lên $160 \mathrm{mgCaCO}_{3} / \mathrm{L}$ (Châu Tài Tảo và ctv., 2015) sau đó lọc qua thiết bị vi lọc $1 \mu \mathrm{m}$ trước khi sử dụng.

\subsection{Nguồn ấu trùng tôm thẻ chân trắng}

Âu trùng Naupllius của tôm thẻ chân trắng có chất lượng tốt được mua từ Công ty $\mathrm{TNHH}$ tôm giống Châu Phi ở tỉnh Ninh Thuận. Ấu trùng được thuần với nguồn nước ở trại khoảng 3 giờ để ấu trùng tôm thích nghi với nguồn nước mới. Sau đó xử lý ấu trùng bằng formol 200 ppm trong 30 giây, rồi định lượng bố trí vào bể ương.

\subsection{Cách tạo biofloc}

Sử dụng nguồn carbon từ đường cát vàng khoáng chất Bien Hoa Pure có $55,54 \% \mathrm{C}$ và $0,19 \% \mathrm{~N}$. Nguồn carbon cần bổ sung vào bể để tạo biofloc được tính dựa theo công thức của Avnimelech (2015).

$$
\Delta \mathrm{CH}=\mathrm{n} * \Delta \mathrm{TAN}
$$

Trong đó:

$\Delta \mathrm{CH}$ : Lượng carbohydrate bổ sung

$\Delta$ TAN: Tổng Ammonia thải vào nước từ thức ăn

$\Delta$ TAN $=$ Lượng thức ăn * N (\%) trong thức ăn * $\mathrm{NH}_{4}{ }^{+}$bài tiết (\%)

$\mathrm{NH}_{4}{ }^{+}$bài tiết: thường chiếm $50 \%(0,5)$ $16 \% \mathrm{~N}$

N (\%)trong thức ăn= Prtein trong thức ăn (\%)*

(Trong đó: $16 \% \mathrm{~N}$ là tỷ lệ nitơ có trong protein)

n: Tỷ lệ $\mathrm{C}: \mathrm{N}$ phụ thuộc vào hiệu suất chuyển hóa của vi sinh vật $(\mathrm{E}=40-60 \%)$

Trong quá trình ương, lượng đường bổ sung dựa vào lượng thức ăn đã tính sằn cho từng nghiệm thức ở giai đoạn từ Mysis 3 và post-larvae, và được ủ trước 48 giờ, sau đó bổ sung trực tiếp vào bể ương, chu kỳ bổ sung đường cát là 1 ngày/lần.

\subsection{Bố trí thí nghiệm}

Thí nghiệm gồm 5 nghiệm thức tỷ lệ $\mathrm{C} / \mathrm{N}$, lặp lại 3 lần, bố trí ngẫu nhiên hoàn toàn. Được tiến hành trong các bể composite $0,5 \mathrm{~m}^{3}$, với độ mặn $30 \%$, mật độ nauplii ban đầu: 150 con/L.

- Nghiệm thức 1: Bổ sung đường cát với tỷ lệ $\mathrm{C} / \mathrm{N}=10$

- Nghiệm thức 2: Bổ sung đường cát với tỷ lệ $\mathrm{C} / \mathrm{N}=15$

- Nghiệm thức 3: Bổ sung đường cát với tỷ lệ $\mathrm{C} / \mathrm{N}=20$

- Nghiệm thức 4: Bổ sung đường cát với tỷ lệ $\mathrm{C} / \mathrm{N}=25$

- Nghiệm thức 5: Bổ sung đường cát với tỷ lệ $\mathrm{C} / \mathrm{N}=30$ 


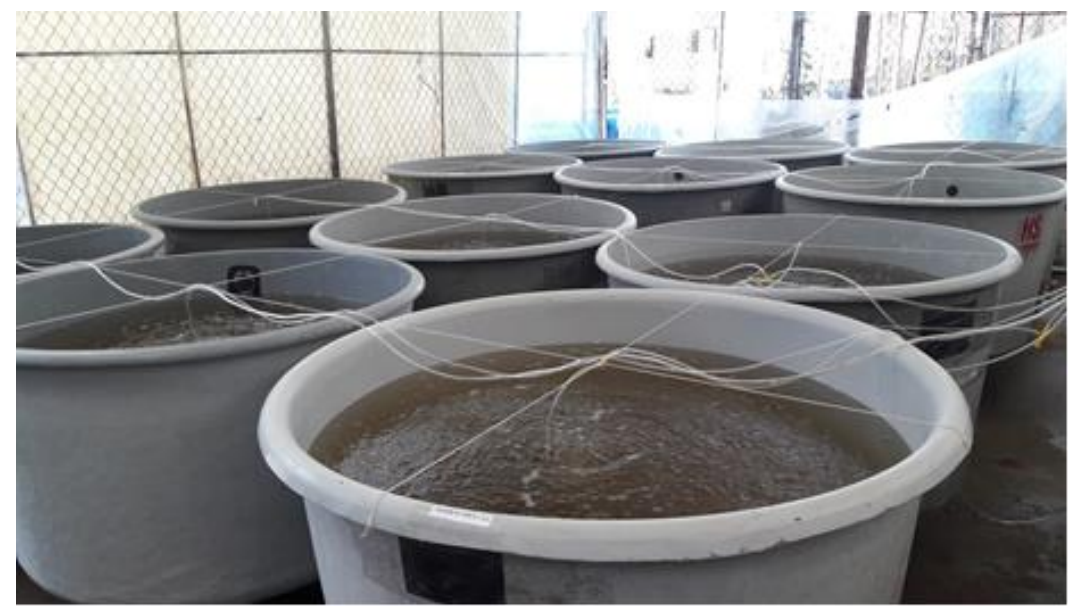

Hình 1: Hệ thống thí nghiệm

\subsection{Chăm sóc ấu trùng và hậu ấu trùng}

Thành phần thức ăn và khẩu phần cho ấu trùng ăn giống nhau ở tất cả các bể thí nghiệm, cho tôm ăn 8 lần/ngày, cách 3 giờ cho ăn 1 lần. Khi ấu trùng nauplli bắt đầu chuyển sang giai đoạn Zoea 1 , tảo tươi Chaetoceros sp. được bổ sung vào bể với mật độ 60.000-120.000 tế bào/mL, mỗi ngày cho ăn 8 lần, cách 3 giờ cho ăn một lần. Ở giai đoạn Zoea 2 và Zoea 3 , tôm được cho ăn thức ăn nhân tạo của Công ty INVE (Thái Lan) theo công thức phối hợp (50\% Lansy $\mathrm{ZM}+50 \%$ Frippak-1) với lượng 0,4 $\mathrm{g} / \mathrm{m}^{3} /$ lần, mỗi ngày cho tôm ăn 8 lần. Giai đoạn ấu trùng Mysis, tôm được cho ăn thức ăn nhân tạo (50\% Lansy $\mathrm{ZM}+50 \%$ Frippak-2) với lượng thức ăn từ $1-1,5 \mathrm{~g} / \mathrm{m}^{3} /$ lần, mỗi ngày cho tôm ăn 4 lần và $2 \mathrm{~g}$ Artemia $/ \mathrm{m}^{3} /$ ần, mỗi ngày cho tôm ăn 4 lần (Artemia được ấp nở đến giai đoạn "bung dù"). Từ giai đoạn PL1 đến PL6 tôm được cho ăn thức ăn Frippak-150 từ $2-3 \mathrm{~g} / \mathrm{m}^{3} /$ lần, mỗi ngày cho tôm ăn 4 lần và Artemia mới nở từ $2-3 \mathrm{~g} / \mathrm{m}^{3} /$ lần, mỗi ngày cho tôm ăn 4 lần; từ PL7 đến PL12 cho ăn thức ăn Lansy PL từ $2-4 \mathrm{~g} / \mathrm{m}^{3} /$ ần, mỗi ngày cho tôm ăn 4 lần và Artemia mới nở từ $3-4 \mathrm{~g} / \mathrm{m}^{3} / 1$ ần, mỗi ngày cho tôm ăn 4 lần (Châu Tài Tảo và ctv., 2020). Lượng thức ăn cho tôm ở các nghiệm thức còn lại sẽ dựa theo nghiệm thức mật độ 150 con/L để tăng lên theo tỷ lệ mật độ của từng nghiệm thức. Trong quá trình ương, chỉ siphon ở giai đoạn cuối Zoea 3, từ giai đoạn Mysis đến cuối thí nghiệm không siphon và chỉ cấp thêm nước do hao hụt.

\subsection{Các chỉ tiêu theo dõi}

Các chỉ tiêu môi trường: Các chỉ tiêu môi trường nước như nhiệt độ và $\mathrm{pH}$, được đo 2 lần/ngày vào lúc $8: 00$ giờ và $14: 00$ giờ bằng nhiệt kế và máy đo $\mathrm{pH}$. Các yếu tố khác như độ kiềm, TAN, và $\mathrm{NO}_{2}^{-}$ được xác định 3 ngày/lần theo phương pháp thu mẫu nước và phân tích trong phòng thí nghiệm. Độ kiềm được phân tích theo phương pháp chuẩn độ acid, TAN được phân tích theo phương pháp Indophenol Blue, $\mathrm{NO}_{2}{ }^{-}$được phân tích theo phương pháp so màu 4500- $\mathrm{NO}_{2}{ }^{-} \mathrm{B}$ (APHA et al., 1995).

Các chỉ tiêu vi sinh: Thu mẫu và phân tích vi khuẩn tổng số và vi khuẩn Vibrio trong nước 1 tuần/lần, và trong tôm (PL12) khi kết thúc thí nghiệm. Mật độ vi khuẩn tổng được xác định bằng phương pháp pha loãng và đếm trên đĩa thạch Nutrient Agar có bổ sung 1,5\% $\mathrm{NaCl}$ (NA) (Huys, 2002). Tương tự, mật độ Vibrio tổng số được xác định bằng phương pháp pha loãng và đếm trên đĩa thạch TCBS (Thiosulfat Citrate Bile Salt Surcose). Cụ thể, mẫu nước ban đầu (nồng độ $10^{\circ}$ ) được pha loãng với nước muối $0,85 \%$ ra 3 nồng độ khác nhau: $10^{-1}, 10^{-2}, 10^{-3}$. Sau đó, hút $100 \mu \mathrm{l}$ từ mỗi nồng độ pha loãng của mẫu nước cho vào đĩa môi trường NA hoặc TCBS, dùng que thủy tinh trang đều, mỗi nồng độ lặp lại 2 lần. Ủ đĩa môi trường ở $28^{\circ} \mathrm{C}$ trong 24 giờ và xác định kết quả. Công thức xác định mật độ vi khuẩn hay Vibrio tổng số như sau:

Mật độ vi khuẩn $(\mathrm{CFU} / \mathrm{m} 1)$ = Số khuẩn lạc $\mathrm{x}$ độ pha loãng x 10

Chỉ tiêu biofloc Kích cỡ hạt biofloc được đo chiều dài và chiều rộng ngẫu nhiên 10 hạt biofloc bằng kính hiển vi có trắc vi thị kính, thể tích biofloc $(\mathrm{ml} / \mathrm{L})$ được xác định bằng cách đong 1 lít nước mẫu cho vào bình nón imhoff và để lắng khoảng 30 phút, ghi nhận thể tích lắng theo đơn vị $\mathrm{ml} / \mathrm{L}$. Các chỉ tiêu biofloc được thu mẫu phân tích ở giai đoạn PL4, PL8 và PL12.

\section{Các chỉ tiêu theo dõi tôm}

- Tăng trưởng của ấu trùng và hậu ấu trùng: chiều dài của ấu trùng và hậu ấu trùng tôm (PL) 
được đo ở các giai đoạn Zoea3, Mysis3, PL4, PL8, và PL12, mỗi bể thu ngẫu nhiên 30 tôm để đo chiều dài tổng trên kính hiển vi có trắc vi thị kính.

- Tỷ lệ sống: khi tôm đạt giai đoạn PL12 thì thu và dùng phương pháp định lượng khối lượng để tính tỷ lệ sống.

- Tỷ lệ sống $(\%)=$ (Số tôm thu được/số tôm ban đầu)*100

- Năng suất của tôm được xác định khi kết thúc thí nghiệm:

Năng suất $(\mathrm{con} / \mathrm{L})=$ Số tôm thu được mỗi bể/thể tích nước trong bể.

Đánh giá chất lượng của tôm PL12: Phương pháp đánh giá chất lượng tôm thẻ chân trắng giống PL12 theo tiêu chuẩn quốc gia TCVN 10257: 2014 (Bộ Khoa học và Công nghệ, 2014).

+ Phương pháp gây sốc bằng formol 100 ppm: thu ngẫu nhiên 100 tôm bột PL12 cho vào cốc chứa $1 \mathrm{~L}$ nước, cho formol vào cốc chứa tôm với nồng độ $100 \mathrm{ppm}$. Sau 30 phút nếu tỷ lệ tôm sống là $100 \%$ là tôm có chất lượng tốt.

+ Phương pháp gây sốc bằng cách hạ độ mặn đột ngột xuống 0 \%o: thu ngẫu nhiên 100 tôm bột PL12 cho vào cốc chứa $1 \mathrm{~L}$ nước ngọt. Sau 30 phút, nếu tỷ lệ tôm sống $100 \%$ thì tôm có chất lượng tốt.

\section{KẾT QUẢ VÀ THẢO LUẬN}

\subsection{Các yếu tố môi trường trong bể nuôi}

Trong suốt thời gian thí nghiệm, nhiệt độ trung bình trong bể ương buổi sáng của các nghiệm thức dao động từ $29,18 \pm 0,23^{\circ} \mathrm{C}$ đến $29,43 \pm 0,01^{\circ} \mathrm{C}$ và buổi chiều từ $30,09 \pm 0,27^{\circ} \mathrm{C}$ dến $30,31 \pm 0,07^{\circ} \mathrm{C}$. Theo Thái Bá Hồ và Ngô Trọng Lư. (2003), nhiệt độ thích hợp cho ấu trùng tôm thẻ chân trắng phát triển tốt từ $28-32^{\circ} \mathrm{C}$.

Giá trị pH ở các nghiệm thức chênh lệch không nhiều giữa các nghiệm thức vào buổi sáng và buổi chiều (Bảng 1). Theo Trần Ngọc Hải và ctv. (2017), $\mathrm{pH}$ thích hợp cho ương ấu trùng tôm thẻ chân trắng từ $7,5-8,5$.

Độ kiềm trung bình của các nghiệm thức dao động từ 144,0 đến $145,3 \mathrm{mgCaCO}_{3} / \mathrm{L}$, giữa các nghiệm thức khác biệt không có ý nghĩa thống kê $(\mathrm{p}>0,05)$ và nằm trong khoảng thích hợp cho ấu trùng tôm phát triển tốt (Bảng 1). Theo Châu Tài Tảo và ctv. (2015), độ kiềm thích hợp cho tăng trưởng và phát triển của ấu trùng và hậu ấu trùng tôm thẻ chân trắng từ $140-160 \mathrm{mgCaCO}_{3} / \mathrm{L}$.

Bảng 1. Các yếu tố môi trường trong bể ương

\begin{tabular}{|c|c|c|c|c|c|c|}
\hline \multirow{2}{*}{\multicolumn{2}{|c|}{ Chỉ tiêu }} & \multicolumn{5}{|c|}{ Nghiệm thức } \\
\hline & & $\mathrm{C} / \mathrm{N}=10$ & $\mathrm{C} / \mathrm{N}=15$ & $\mathrm{C} / \mathrm{N}=20$ & $\mathrm{C} / \mathrm{N}=25$ & $\mathrm{C} / \mathrm{N}=\mathbf{3 0}$ \\
\hline \multirow{2}{*}{$\begin{array}{l}\text { Nhiệt độ } \\
\left({ }^{\circ} \mathrm{C}\right)\end{array}$} & Sáng & $29,37 \pm 0,07$ & $29,43 \pm 0,01$ & $29,39 \pm 0,02$ & $29,33 \pm 0,07$ & $29,18 \pm 0,23$ \\
\hline & Chiều & $30,14 \pm 0,04$ & $30,31 \pm 0,07$ & $30,09 \pm 0,27$ & $30,30 \pm 0,01$ & $30,26 \pm 0,03$ \\
\hline \multirow{2}{*}{$\mathrm{pH}$} & Sáng & $7,90 \pm 0,01$ & $7,90 \pm 0,02$ & $7,92 \pm 0,02$ & $7,92 \pm 0,04$ & $7,91 \pm 0,03$ \\
\hline & Chiều & $8,13 \pm 0,01$ & $8,14 \pm 0,01$ & $8,13 \pm 0,01$ & $8,13 \pm 0,01$ & $8,14 \pm 0,01$ \\
\hline \multirow{3}{*}{\multicolumn{2}{|c|}{$\begin{array}{l}\text { Độ kiềm }\left(\mathrm{mgCaCO}_{3} / \mathrm{L}\right) \\
\text { TÁN }(\mathrm{mg} / \mathrm{L}) \\
\mathrm{NO}_{2}{ }^{-}(\mathrm{mg} / \mathrm{L})\end{array}$}} & $144,0 \pm 1,5^{\mathrm{a}}$ & $145,3 \pm 0,7^{\mathrm{a}}$ & $145,1 \pm 1,0^{\mathrm{a}}$ & $144,9 \pm 0,9^{\mathrm{a}}$ & $144,5 \pm 0,5^{\mathrm{a}}$ \\
\hline & & $0,82 \pm 0,04^{b}$ & $0,74 \pm 0,04^{\mathrm{a}}$ & $0,71 \pm 0,01^{\mathrm{a}}$ & $0,72 \pm 0,02^{\mathrm{a}}$ & $0,75 \pm 0,04^{\mathrm{a}}$ \\
\hline & & $0,57 \pm 0,02^{\mathrm{b}}$ & $0,42 \pm 0,06^{\mathrm{a}}$ & $0,48 \pm 0,03^{\mathrm{a}}$ & $0,45 \pm 0,02^{\mathrm{a}}$ & $0,44 \pm 0,02^{\mathrm{a}}$ \\
\hline
\end{tabular}

Các số liệu trong cùng một hàng có chũ cái giống nhau thì khác biệt không có ý nghĩa thống kê $(p<0,05)$

Bảng 1 cho thấy hàm lượng TAN ở nghiệm thức tỷ lệ $\mathrm{C} / \mathrm{N}=10$ cao nhất khác biệt có ý nghĩa thống kê $(\mathrm{p}<0,05)$ so với các nghiệm thức còn lại. Theo Boyd và Tucker (1998) và Chanratchakool (2003), hàm lượng TAN thích hợp cho ấu trùng tôm nhỏ hơn 2 $\mathrm{mg} / \mathrm{L}$.

Cũng giống như hàm lượng TAN, hàm lượng $\mathrm{NO}_{2}^{-}$cao nhất ở nghiệm thức tỷ lệ $\mathrm{C} / \mathrm{N}=10$ khác biệt không có ý nghĩa thống kê so với các nghiệm thức còn lại, $\mathrm{NO}_{2}{ }^{-}$thấp nhất ở nghiệm thức tỷ lệ $\mathrm{C} / \mathrm{N}=15$. Theo Phạm Văn Tình (2004) hàm lượng $\mathrm{NO}_{2}{ }^{-}<1 \mathrm{mg} / \mathrm{L}$ nằm trong khoảng thích hợp cho sự phát triển của ấu trùng tôm.
Nhìn chung, các yếu tố môi trường trong bể ương của các nghiệm thức đều nằm trong khoảng thích hợp cho ấu trùng và hậu ấu trùng tôm thẻ chân trắng phát triển tốt.

\subsection{Vi khuẩn tổng và vi khuẩn Vibrio}

\subsubsection{Vi khuẩn tổng}

Mật độ vi khuẩn tổng ở các nghiệm thức sau 7 ngày ương giữa các nghiệm thức khác biệt không có ý nghĩa thống kê $(\mathrm{p}>0,05)$ (Bảng 2). Sau 14 ngày và 21 ngày ương, mật độ vi khuẩn tổng cao nhất ở nghiệm thức $\mathrm{C} / \mathrm{N}=30$ khác biệt không có ý nghĩa thống kê $(\mathrm{p}>0,05)$ so với nghiệm thức $\mathrm{C} / \mathrm{N}=25$, 
nhưng khác biệt có ý nghĩa thống kê $(\mathrm{p}<0,05)$ so với các nghiệm thức còn lại.

Vi khuẩn tổng trong tôm khi kết thúc thí nghiệm dao động từ $2,67 * 10^{3} \mathrm{CFU} / \mathrm{g}$ đến $4,33 * 10^{3} \mathrm{CFU} / \mathrm{g}$, Mật độ vi khuẩn tổng trong tôm cao nhất ở nghiệm thức $\mathrm{C} / \mathrm{N}=30$ khác biệt không có ý nghĩa thống kê ( $\mathrm{p}>0,05$ ) so với nghiệm thức $\mathrm{C} / \mathrm{N}=25$, nhưng khác biệt có ý nghĩa thống kê $(\mathrm{p}<0,05)$ với các nghiệm thức còn lại.
Theo Châu Tài Tảo và ctv. (2020), mật độ vi khuẩn tổng trong nước ở nghiệm thức bổ sung đường cát sau 21 ngày ương là $11,83 \pm 0,76^{*} 10^{3}$ $\mathrm{CFU} / \mathrm{mL}$ và trong tôm $6,13 \pm 2,02 * 10^{3} \mathrm{CFU} / \mathrm{g} \mathrm{khi}$ ương ấu trùng tôm thẻ chân trắng theo công nghệ biofloc thì tôm dẫn phát triển tốt. Kết quả nghiên cứu này ở các nghiệm thức đều thấp hơn, vì vậy mật độ vi khuẩn tổng trong nước và trong tôm ở các nghiệm thức nằm trong khoảng thích hợp cho ấu trùng và hậu ấu trùng tôm phát triển tốt.

Bảng 2. Mật độ vi khuẩn tổng của các nghiệm thức $\left(10^{3} \mathrm{CFU} / \mathrm{mL}\right.$ trong nước và $10^{3} \mathrm{CFU} / \mathrm{g}$ trong tôm)

\begin{tabular}{crrrr}
\hline \multirow{2}{*}{ Nghiệm thức } & \multicolumn{3}{c}{ Trong nước ương tôm } & \multirow{2}{*}{ Trong tôm } \\
\cline { 2 - 4 } & $\mathbf{7 ~ n g a ̀ y ~}$ & $\mathbf{1 4}$ ngày & $\mathbf{2 1}$ ngày & \\
\hline $\mathrm{C} / \mathrm{N}=10$ & $0,14 \pm 0,02^{\mathrm{a}}$ & $2,20 \pm 0,10^{\mathrm{a}}$ & $2,97 \pm 0,45^{\mathrm{a}}$ & $2,67 \pm 0,21^{\mathrm{a}}$ \\
$\mathrm{C} / \mathrm{N}=15$ & $0,17 \pm 0,06^{\mathrm{a}}$ & $2,27 \pm 0,32^{\mathrm{a}}$ & $3,20 \pm 1,01^{\mathrm{a}}$ & $2,87 \pm 0,31^{\mathrm{a}}$ \\
$\mathrm{C} / \mathrm{N}=20$ & $0,14 \pm 0,01^{\mathrm{a}}$ & $2,37 \pm 0,45^{\mathrm{a}}$ & $3,10 \pm 0,79^{\mathrm{a}}$ & $3,07 \pm 0,71^{\mathrm{a}}$ \\
$\mathrm{C} / \mathrm{N}=25$ & $0,14 \pm 0,02^{\mathrm{a}}$ & $3,10 \pm 0,40^{\mathrm{b}}$ & $4,80 \pm 0,72^{\mathrm{b}}$ & $3,77 \pm 0,42^{\mathrm{ab}}$ \\
$\mathrm{C} / \mathrm{N}=30$ & $0,15 \pm 0,02^{\mathrm{a}}$ & $3,70 \pm 0,51^{\mathrm{b}}$ & $5,83 \pm 1,15^{\mathrm{b}}$ & $4,33 \pm 1,06^{\mathrm{b}}$ \\
\hline
\end{tabular}

Các số liệu trong cùng một cột có chũ cái giống nhau thì khác biệt không có ý nghĩa thống kê $(p<0,05)$

\subsubsection{Vi khuẩn Vibrio}

Mật độ vi khuẩn Vibrio trong nước và trong tôm được trình bày ở Bảng 3. Sau 7 ngày ương, mật độ vi khuẩn Vibrio ở các nghiệm thức khác biệt không có ý nghĩa thống kê $(\mathrm{p}>0,05)$. Đến 14 ngày ương, mật độ vi khuẩn Vibrio thấp nhất ở nghiệm thức tỷ lệ $\mathrm{C} / \mathrm{N}=10$ khác biệt có ý nghĩa thống kê $(\mathrm{p}<0,05)$ so với nghiệm thức tỷ lệ $\mathrm{C} / \mathrm{N}=30$ nhưng khác biệt không có ý nghĩa thống kê so với các nghiệm thức còn lại. Đến 21 ngày ương, mật độ vi khuẩn Vibrio trong nước và trong tôm cao nhất ở nghiệm thức tỷ lệ $\mathrm{C} / \mathrm{N}=30$ khác biệt có ý nghĩa thống kê $(\mathrm{p}<0,05)$ so với các nghiệm thức còn lại. Theo Châu Tài Tảo và ctv. (2018), ương ấu trùng tôm sú theo công nghệ biofloc bằng cách bổ sung rỉ đường ở các giai đoạn khác nhau thì mật độ vi khuẩn Vibrio bằng $30,83 \times 10^{3} \mathrm{CFU} / \mathrm{mL}$ trong nước và $30,9 \times 10^{3} \mathrm{CFU} / \mathrm{g}$ trong tôm nhưng chưa thấy ảnh hưởng đến ấu trùng và hậu ấu trùng tôm. Nhìn chung, mật độ vi khuẩn Vibrio qua các lần thu mẫu của các nghiệm thức vẫn nằm trong khoảng thích hợp cho âu trùng tôm thẻ chân trắng phát triển tốt.

Bảng 3. Mật độ vi khuẩn Vibrio của các nghiệm thức $\left(10^{3} \mathrm{CFU} / \mathrm{mL}\right.$ trong nước và $10^{3} \mathrm{CFU} / \mathrm{g}$ trong tôm)

\begin{tabular}{ccccc}
\hline \multirow{2}{*}{ Nghiệm thức } & \multicolumn{3}{c}{ Trong nước ương tôm } & \multirow{2}{*}{ Trong tôm } \\
\cline { 2 - 4 } & $\mathbf{7 ~ n g a ̀ y ~}$ & $\mathbf{1 4}$ ngày & $\mathbf{2 1 ~ n g a ̀ y ~}$ & \\
\hline $\mathrm{C} / \mathrm{N}=10$ & $0,37 \pm 0,07^{\mathrm{a}}$ & $0,47 \pm 0,13^{\mathrm{a}}$ & $0,76 \pm 0,05^{\mathrm{a}}$ & $0,50 \pm 0,17^{\mathrm{a}}$ \\
$\mathrm{C} / \mathrm{N}=15$ & $0,38 \pm 0,08^{\mathrm{a}}$ & $0,51 \pm 0,05^{\mathrm{a}}$ & $0,93 \pm 0,15^{\mathrm{a}}$ & $0,40 \pm 0,20^{\mathrm{a}}$ \\
$\mathrm{C} / \mathrm{N}=20$ & $0,46 \pm 0,06^{\mathrm{a}}$ & $0,50 \pm 0,16^{\mathrm{a}}$ & $0,88 \pm 0,09^{\mathrm{a}}$ & $0,37 \pm 0,15^{\mathrm{a}}$ \\
$\mathrm{C} / \mathrm{N}=25$ & $0,47 \pm 0,09^{\mathrm{a}}$ & $0,94 \pm 0,06^{\mathrm{ab}}$ & $0,97 \pm 0,06^{\mathrm{a}}$ & $0,70 \pm 0,20^{\mathrm{a}}$ \\
$\mathrm{C} / \mathrm{N}=30$ & $0,44 \pm 0,08^{\mathrm{a}}$ & $1,23 \pm 0,72^{\mathrm{b}}$ & $1,93 \pm 0,15^{\mathrm{b}}$ & $1,07 \pm 0,15^{\mathrm{b}}$ \\
\hline
\end{tabular}

Các số liệu trong cùng một cột có chũ cái giống nhau thì khác biệt không có ý nghĩa thống kê $(p<0,05)$

\subsection{Thể tích và kích thước hạt biofloc}

Kết quả thí nghiệm cho thấy thể tích biofloc của các nghiệm thức tăng dần qua các lần thu mẫu, nghiệm thức tỷ lệ $\mathrm{C} / \mathrm{N}$ càng cao thì thể tích biofloc càng lớn. Ở giai đoạn PL4, thể tích biofloc ở nghiệm thức $\mathrm{C} / \mathrm{N}=10$ thấp nhất khác biệt có ý nghĩa thống kê $(\mathrm{p}<0,05)$ so với các nghiệm thức còn lại. Thể tích biofloc ở giai đoạn PL8 và PL12 cao nhất ở nghiệm thức $\mathrm{C} / \mathrm{N}=30$ và khác biệt có ý nghĩa thống kê $(\mathrm{p}<0,05)$ so với các nghiệm thức còn lại, thấp nhất là ở nghiệm thức $\mathrm{C} / \mathrm{N}=10$ khác biệt không có ý nghĩa thống kê $(\mathrm{p}>0,05)$ so với nghiệm thức $\mathrm{C} / \mathrm{N}=15$, nhưng khác biệt có ý nghĩa thống kê $(\mathrm{p}<0,05)$ so với các nghiệm thức còn lại.

Chiều rộng hạt biofloc ở giai đoạn PL4 cho thấy nghiệm thức tỷ lệ $\mathrm{C} / \mathrm{N}=10$ nhỏ nhất khác biệt có ý nghĩa thống kê $(\mathrm{p}<0,05)$ so với nghiệm thức tỷ lệ $\mathrm{C} / \mathrm{N}=30$, nhưng khác biệt không có ý nghĩa thống kê ( $p>0,05)$ so với các nghiệm thức còn lại. Ở giai đoạn PL8 và PL12, chiều rộng hạt biofloc lớn nhất ở 
nghiệm thức tỷ lệ $\mathrm{C} / \mathrm{N}=30$ khác biệt không có ý nghĩa thống kê $(\mathrm{p}>0,05)$ so với nghiệm thức tỷ lệ $\mathrm{C} / \mathrm{N}=25$, nhưng khác biệt có ý nghĩa thống kê $(\mathrm{p}<0,05)$ so với các nghiệm thức còn lại.

Ở giai đoạn PL4, chiều dài hạt biofloc của các nghiệm thức khác biệt không có ý nghĩa thống kê $(\mathrm{p}>0,05)$. Đến giai đoạn PL8 và PL12 các nghiệm thức tỷ lệ $\mathrm{C} / \mathrm{N}=20, \mathrm{C} / \mathrm{N}=25$ và $\mathrm{C} / \mathrm{N}=30$ chiều dài hạt biofloc giữa các nghiệm thức khác biệt không có ý nghĩa thống kê ( $\mathrm{p}>0,05)$, nhưng khác biệt có ý nghĩa thống kê $(p<0,05)$ so với 2 nghiệm thức còn lại. Theo thời gian ương, kích thước hạt biofloc có xu hướng tăng lên, nghiệm thức tỷ lệ $\mathrm{C} / \mathrm{N}$ càng cao thì kích thức hạt biofloc càng lớn. Các chỉ tiêu biofloc có vai trò vừa cải thiện môi trường nước vừa làm thức ăn cho tôm (Avnimelech, 2015).

\section{Bảng 4. Thể tích và kích thước hạt biofloc}

\begin{tabular}{lcrrrrr}
\hline \multirow{2}{*}{ Chỉ tiêu } & & \multicolumn{5}{c}{ Nghiệm thức } \\
\cline { 3 - 6 } & & $\mathbf{C} / \mathbf{N}=\mathbf{1 0}$ & $\mathbf{C} / \mathbf{N}=\mathbf{1 5}$ & $\mathbf{C} / \mathbf{N}=\mathbf{2 0}$ & $\mathbf{C} / \mathbf{N}=\mathbf{2 5}$ & $\mathbf{C} / \mathbf{N}=\mathbf{3 0}$ \\
\hline \multirow{2}{*}{ Thể tích } & PL4 & $0,70 \pm 0,10^{\mathrm{a}}$ & $0,08 \pm 0,10^{\mathrm{a}}$ & $1,07 \pm 0,15^{\mathrm{b}}$ & $1,13 \pm 0,08^{\mathrm{b}}$ & $1,23 \pm 0,06^{\mathrm{b}}$ \\
(mL/L) & PL8 & $1,15 \pm 0,06^{\mathrm{a}}$ & $1,17 \pm 0,05^{\mathrm{a}}$ & $1,36 \pm 0,06^{\mathrm{b}}$ & $1,46 \pm 0,12^{\mathrm{b}}$ & $1,89 \pm 0,09^{\mathrm{c}}$ \\
& PL12 & $1,63 \pm 0,15^{\mathrm{a}}$ & $1,83 \pm 0,21^{\mathrm{a}}$ & $2,57 \pm 0,32^{\mathrm{b}}$ & $2,87 \pm 0,31^{\mathrm{b}}$ & $3,43 \pm 0,31^{\mathrm{c}}$ \\
\hline Chiều & PL4 & $0,12 \pm 0,01^{\mathrm{a}}$ & $0,12 \pm 0,01^{\mathrm{a}}$ & $0,14 \pm 0,02^{\mathrm{ab}}$ & $0,14 \pm 0,01^{\mathrm{ab}}$ & $0,15 \pm 0,01^{\mathrm{b}}$ \\
rộng & PL8 & $0,15 \pm 0,01^{\mathrm{a}}$ & $0,16 \pm 0,02^{\mathrm{a}}$ & $0,16 \pm 0,01^{\mathrm{a}}$ & $0,17 \pm 0,02^{\mathrm{ab}}$ & $0,19 \pm 0,02^{\mathrm{b}}$ \\
(mm) & PL12 & $0,18 \pm 0,01^{\mathrm{a}}$ & $0,19 \pm 0,02^{\mathrm{a}}$ & $0,19 \pm 0,01^{\mathrm{a}}$ & $0,21 \pm 0,02^{\mathrm{ab}}$ & $0,22 \pm 0,01^{\mathrm{b}}$ \\
\hline Chiều & PL4 & $0,21 \pm 0,01^{\mathrm{a}}$ & $0,22 \pm 0,01^{\mathrm{a}}$ & $0,23 \pm 0,02^{\mathrm{a}}$ & $0,23 \pm 0,02^{\mathrm{a}}$ & $0,24 \pm 0,02^{\mathrm{a}}$ \\
dài & PL8 & $0,28 \pm 0,02^{\mathrm{a}}$ & $0,29 \pm 0,01^{\mathrm{a}}$ & $0,32 \pm 0,02^{\mathrm{b}}$ & $0,33 \pm 0,01^{\mathrm{b}}$ & $0,32 \pm 0,02^{\mathrm{b}}$ \\
(mm) & PL12 & $0,32 \pm 0,01^{\mathrm{a}}$ & $0,34 \pm 0,01^{\mathrm{a}}$ & $0,39 \pm 0,01^{\mathrm{b}}$ & $0,37 \pm 0,02^{\mathrm{b}}$ & $0,39 \pm 0,02^{\mathrm{b}}$ \\
\hline
\end{tabular}

Các số liệu trong cùng một hàng có chũ cái giống nhau thì khác biệt không có ý nghĩa thống kê $(p<0,05)$

\subsection{Chiều dài của ấu trùng và hậu ấu trùng tôm thẻ chân trắng}

Trong ương ấu trùng tôm thẻ chân trắng, chỉ tiêu chiều dài đánh giá tăng trưởng của tôm ở từng nghiệm thức và được trình bày ở Bảng 5 . Qua kêt quả xử lý thống kê tăng trưởng về chiều dài của tôm, ở giai đoạn Zoea3 và Mysis 3 chiều dài của tôm giữa các nghiệm thức khác biệt không có ý nghĩa thống kê $(\mathrm{p}>0,05)$.

Đến giai đoạn PL4 và PL8, chiều dài của tôm lớn nhất ở nghiệm thức $\mathrm{C} / \mathrm{N}=20$, nhưng khác biệt không có ý nghĩa thống kê $(\mathrm{p}>0,05)$ so với các nghiệm thức còn lại. Đến giai đoạn PL12 chiều dài của tôm lớn nhất ở nghiệm thức $\mathrm{C} / \mathrm{N}=20$, khác biệt có ý nghĩa thống kê $(\mathrm{p}<0,05)$ so với nghiệm thức $\mathrm{C} / \mathrm{N}=10$ và $\mathrm{C} / \mathrm{N}=15$, nhưng khác biệt không có ý nghĩa thống kê $(\mathrm{p}>0,05)$ so với 2 nghiệm thức còn lại. Chiều dài của PL12 thấp nhất ở nghiệm thức $\mathrm{C} / \mathrm{N}=10$ khác biệt không có ý nghĩa thống kê ( $\mathrm{p}>0,05)$ so với nghiệm thức $\mathrm{C} / \mathrm{N}=15$, nhưng khác biệt có ý nghĩa thống kê $(\mathrm{p}<0,05)$ so với các nghiệm thức còn lại.

Bảng 5. Chiều dài $(\mathrm{mm})$ của ấu trùng và hậu ấu trùng tôm thẻ chân trắng

\begin{tabular}{lrrrrr}
\hline \multirow{2}{*}{ Giai đoạn } & \multicolumn{5}{c}{ Nghiệm thức } \\
\cline { 2 - 6 } & $\mathbf{C} / \mathbf{N}=\mathbf{1 0}$ & $\mathbf{C} / \mathbf{N}=\mathbf{1 5}$ & $\mathbf{C} / \mathbf{N}=\mathbf{2 0}$ & $\mathbf{C} / \mathbf{N}=\mathbf{2 5}$ & $\mathbf{C} / \mathbf{N}=\mathbf{3 0}$ \\
\hline Zoae3 & $2,58 \pm 0,02^{\mathrm{a}}$ & $2,55 \pm 0,01^{\mathrm{a}}$ & $2,55 \pm 0,02^{\mathrm{a}}$ & $2,54 \pm 0,01^{\mathrm{a}}$ & $2,56 \pm 0,03^{\mathrm{a}}$ \\
Mysis3 & $3,93 \pm 0,02^{\mathrm{a}}$ & $3,93 \pm 0,05^{\mathrm{a}}$ & $3,92 \pm 0,03^{\mathrm{a}}$ & $3,90 \pm 0,01^{\mathrm{a}}$ & $3,91 \pm 0,02^{\mathrm{a}}$ \\
PL4 & $5,97 \pm 0,19^{\mathrm{a}}$ & $5,98 \pm 0,23^{\mathrm{a}}$ & $6,08 \pm 0,10^{\mathrm{a}}$ & $6,03 \pm 0,50^{\mathrm{a}}$ & $6,01 \pm 0,17^{\mathrm{a}}$ \\
PL8 & $8,61 \pm 0,05^{\mathrm{a}}$ & $8,64 \pm 0,06^{\mathrm{a}}$ & $8,65 \pm 0,03^{\mathrm{a}}$ & $8,64 \pm 0,09^{\mathrm{a}}$ & $8.62 \pm 0,12^{\mathrm{a}}$ \\
PL12 & $9,99 \pm 0,10^{\mathrm{a}}$ & $10,19 \pm 0,21^{\mathrm{ab}}$ & $10,53 \pm 0,07^{\mathrm{c}}$ & $10,33 \pm 0,12^{\mathrm{bc}}$ & $10,28 \pm 0,16^{\mathrm{bc}}$ \\
\hline
\end{tabular}

Các số liệu trong cùng một hàng có chũ cái giống nhau thì khác biệt không có ý nghĩa thống kê $(p<0,05)$

\subsection{Tỷ lệ sống và năng suất của PL12}

Qua kết quả xử lý thống kê, tỷ lệ sống của PL12 ở nghiệm thức có sự khác biệt, nghiệm thức $\mathrm{C} / \mathrm{N}=20$ cao nhất $(60,9 \%)$ khác biệt có ý nghĩa thống kê $(\mathrm{p}<0,05)$ so với các nghiệm thức còn lại (Bảng 6). Kế đến là ở nghiệm thức $\mathrm{C} / \mathrm{N}=15$ cũng khác biệt có ý nghĩa thống kề $(\mathrm{p}<0,05)$ so với các nghiệm thức còn lại. Tỷ lệ sống của tôm thấp nhất là ở nghiệm thức $\mathrm{C} / \mathrm{N}=30$.

Cũng giống như tỷ lệ sống, năng suất của PL12 cao nhất là ở nghiệm thức $\mathrm{C} / \mathrm{N}=20$ khác biệt có ý nghĩa thống kê $(\mathrm{p}<0,05)$ so với các nghiệm thức còn lại. Năng suất của PL12 thấp nhất ở nghiệm thức $\dot{\mathrm{C}} / \mathrm{N}=30$ là $61.500 \mathrm{con} / \mathrm{m}^{3}$. 
Bảng 6. Tỷ lệ sống và năng suất của PL-12 ở các nghiệm thức

\begin{tabular}{crr}
\hline \multirow{2}{*}{$\begin{array}{c}\text { Nghiệm } \\
\text { thức }\end{array}$} & \multicolumn{2}{c}{ Chỉ tiêu } \\
\cline { 2 - 3 } & $\begin{array}{r}\text { Tỷ lệ sống } \\
(\%)\end{array}$ & $\begin{array}{r}\text { Năng suất } \\
\left(\mathbf{c o n} / \mathbf{m}^{\mathbf{3}}\right)\end{array}$ \\
\hline $\mathrm{C} / \mathrm{N}=10$ & $52,0 \pm 0,7^{\mathrm{b}}$ & $78.000 \pm 1.000^{\mathrm{b}}$ \\
$\mathrm{C} / \mathrm{N}=15$ & $56,0 \pm 1,8^{\mathrm{c}}$ & $84.004 \pm 2.754^{\mathrm{c}}$ \\
$\mathrm{C} / \mathrm{N}=20$ & $60,9 \pm 1,4^{\mathrm{d}}$ & $91.449 \pm 2.094^{\mathrm{d}}$ \\
$\mathrm{C} / \mathrm{N}=25$ & $52,1 \pm 2,0^{\mathrm{b}}$ & $78.072 \pm 2.909^{\mathrm{b}}$ \\
$\mathrm{C} / \mathrm{N}=30$ & $41,0 \pm 2,0^{\mathrm{a}}$ & $61.500 \pm 3.000^{\mathrm{a}}$ \\
\hline
\end{tabular}

Các số liệu trong cùng một cột có chũ cái giống nhau thì khác biệt không có ý nghĩa thống kê $(p<0,05)$

\section{6. Đánh giá chất lượng tôm PL12}

Đánh giá chất lượng tôm thẻ chân trắng giống là rất quan trọng khi đưa ra thị trường nhằm đảm bảo tôm đạt tiêu chuẩn và chất lượng, phương pháp đánh giá chất lượng ấu trùng thường sử dụng là sốc formol và sốc độ mặn.

Sau khi sốc tôm PL12 bằng formol 100 ppm và độ mặn $0 \%$ thì tất cả các nghiệm thức đều có tỷ lệ tôm sống đạt $100 \%$, kết quả này phù hợp với tiêu chuẩn quốc gia TCVN 10257: 2014

\section{KẾT LUẬN VÀ ĐỀ XUẤT}

\subsection{Kết luận}

Các chỉ tiêu môi trường, vi sinh và biofloc nằm trong khoảng thích hợp cho ấu trùng và hậu ấu trùng tôm thẻ chân trắng phát triển tốt.

Chiều dài PL12 $(10,53 \pm 0,07 \mathrm{~mm})$, tỷ lệ sống $(60,9 \pm 1,4 \%)$ và năng suất $\left(91.449 \pm 2.094 \mathrm{con} / \mathrm{m}^{3}\right)$ của tôm ở nghiệm thức $\mathrm{C} / \mathrm{N}=20$ là tốt nhất.

Sốc tôm PL12 bằng formol $100 \mathrm{ppm}$ và giảm $50 \%$ độ mặn cho thấy tỷ lệ sống của tôm PL12 thu được từ các nghiệm thức $\mathrm{C} / \mathrm{N}$ khác nhau đều có chất lượng tốt

\section{2. Đề xuất}

Úng dụng công nghệ biofloc với việc bổ sung đường cát với tỷ lệ $\mathrm{C} / \mathrm{N}=20$ để thực hiện các nghiên cứu tiếp theo nhằm xây dựng quy trình ương ấu trùng tôm thẻ chân trắng theo công nghệ biofloc để ứng dụng vào thực tế sản xuất.

\section{LỜI CẢM TẠ}

Đề tài này được tài trợ bởi Dự án Nâng cấp Trường Đại học Cần Thơ VN14-P6 bằng nguồn vốn vay ODA từ Chính phủ Nhật Bản.

\section{TÀI LIỆU THAM KHẢO}

APHA, AWWA, \& WEF. (1995). Standard methods for the examination of water and wastewater (19 ${ }^{\text {th }}$ ed.). American Public Health Association, Washington DC.
Avnimelech, Y. (2015). Biofloc Technology - A Practical Guide Book ( $3^{\text {rd }}$ ed.). The World Aquaculture Society, Baton Rouge, Louisiana, United States.

Bộ Khoa học và Công Nghệ. (2014). Quyết định 1990/QĐ-BKHCN ngày 04 tháng 08 năm 2014 công bố Tiêu chuẩn quốc gia TCVN 10257:2014 về Tôm thẻ chân trắng - Tôm giống - Yêu cầu kỹ thuật do Bộ trưởng Bộ Khoa học và Công nghệ ký ban hành.

Boyd, C.E., \& Tucker, C.S. (1998). Pond Aquaculture Water Quality Management. Kluwer Academic Publishers. Boston, Massachusetts.

Chanratchakool, P. (2003). Advice on aquatic animal health care: Problems in Penaeus monodon culture in low salinity areas. Aquaculture Asia, 8(1), 54-56.

Châu Tài Tảo, Lý Văn Khánh \& Trần Ngọc Hải. (2018). Nghiên cứu ương ấu trùng tôm sú (Penaeus monodon) bằng công nghệ biofloc từ nguồn carbohydrate rỉ đường bổ sung ở các giai đoạn khác nhau. Tạp chí Khoa học Truờng Đại hoc Cần Tho, 54(1), 27-34.

Châu Tài Tảo, Trần Ngọc Hải \& Nguyễn Thanh Phương. (2015). Ảnh hưởng của độ kiềm lên tăng trưởng và tỷ lệ sống của ấu trùng và hậu ấu trùng tôm chân trắng (Litopenaeus vannamei). Tạp chí Nông nghiệp và phát triển nông thôn, 14, 110 - 115.

Châu Tài Tảo, Trần Nguyễn Duy Khoa, Nguyễn Văn Hòa \& Trần Ngọc Hải. (2020). Nghiên cứu ương ấu trùng tôm chân trắng (Litopenaeus vannamei) theo công nghệ biofioc với các nguồn carbon bổ sung khác nhau. Tạp chí Khoa học Trường Đại học Cần Tho, 56(Số chuyên đề Thủy sản)(2), 29-36.

Huys, G. 2002. Preservation of bacteria using commercial cryopreservation systems. Standard Operation Procedure, SOP Asia-Resist-Press.

McIntosh, B. J., Samocha, T. M., Jones, E. R., Lawrence, A. L., McKee, D. A., Horowitz, S. \& Horowitz, A. (2000). The effect of a bacterial supplement on the high-density culturing of Litopenaeus vannamei with low-protein diet on outdoor tank system and no water exchange. Aquacultural Engineering, 21, 215-227.

Phạm Văn Tình. (2004). Kỹ thuật nuôi tôm sú chất lượng cao. Nhà xuất bản Nông nghiệp.

Thái Bá Hồ \& Ngô Trọng Lư. (2003). Kỹ thuật nuôi tôm he chân trắng. Nhà xuất bản Nông nghiệp Hà Nội.

Tổng cục Thủy sản. (2017). Sản xuất tôm giống - nền móng của ngành tôm hiện đại.

https://tongcucthuysan.gov.vn/vivn/Nuôitrồngthủysản/-Sản-xuấtgiống/doctin/006970/201702-13/sanxuat-tomgiong-nenmong-cuanganh-tom-hien-dai

Trần Ngọc Hải, Châu Tài Tảo \& Nguyễn Thanh Phương. (2017). Giáo trình Kỹ thuật sản xuất giống và nuôi giáp xác. Nhà xuất bản Đại học Cần Thơ. 